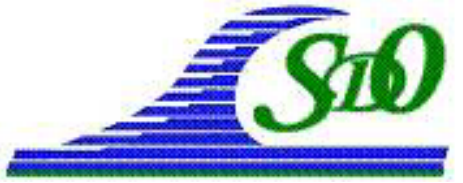

\title{
Dredged marine sand as construction material
}

\author{
Jussara LIMEIRA ${ }^{1}$, Luis AGULLÓ ${ }^{1}$, Miren ETXEBERRIA ${ }^{1}$
}

1. Universitat Politecnica de Catalunya, UPC, Jordi Girona, 1-3, 08034 Barcelone, Spain.

jussara.limeira@upc.edu ; luis.agullo@upc.edu ;miren.etxeberria@upc.edu

\begin{abstract}
:
Dredging works are usually required to maintenance activities in many ports all over the world and represents a huge volume of disposal material. The use of dredged aggregates can be considered in several applications as erosive process control, coastal stabilization, beach replenishment, production of construction materials (clay, bricks, aggregates) or construction works (foundation fill, dikes, etc.).

Researches revealed the feasibility of dredged marine sand (DMS) in the construction of base and sub-base harbour pavements incorporating this material to hydraulic binder mixes (cement or lime) in order to improve the grading of aggregates and correct the granular skeleton. Its main objective is to improve the packing and to obtain the compressive properties required for geotechnical applications.

In this work the study of DMS from the Port of Sant Carles de la Rápita (Tarragona, Spain) as construction material is presented. The analysis of its influence on paste, mortar and concrete production is described. Two experimental phases were carried out once chemical and physical characteristics of DMS were determined. At first, pastes and mortars were made using CEM II/A-M 42,5R cement, different percentages of DMS on replacement of raw sand and plasticizer additive in order to obtain fresh and hardened properties of the mixes studied. After that, DMS was used in the production of concretes as fine aggregates. A pilot experience was carried out with concrete port pavements produced in industrial scale. Fresh and hardened properties of the concretes were determined and compared to the control mix. Results show satisfactory behaviour of DMS as construction material when incorporated in concrete as fine corrective sand.
\end{abstract}

\section{Keywords:}

Dredged marine sand - Mortar - Concrete - Mechanical properties

\section{Introduction}

In the present work a study about the use of dredged marine sand (DMS) as construction material is described. Different samples from Sant Carles de la Rapita Port (Spain) were used for pastes, mortar and concrete production. Chemical, physical and mechanical characteristics were determined. DMS chemical characterisation indicated a negligible contaminant level in all samples studied as described on LIMEIRA et al. (in press). According to sieve analysis all samples were characterized as fine material (more than 
90\% passes through sieve \#250 $\mu \mathrm{m}$ ) but negligible fine content was found (less than $1 \%$ passes through sieve $\# 63 \mu \mathrm{m})$. Experimental tests were carried out on pastes and mortars fabricated with different DMS content. The objective was to evaluate its influence in the mixes behaviour with respect to cohesion, workability and strength resistance comparing to control mixes. Concrete was produced in industrial scale in a homologated plant and used in the execution of three experimental sections of a harbour pavement (15 m long, $5 \mathrm{~m}$ wide and $25 \mathrm{~cm}$ thick, see figure 1). Three different concretes were produced: C1 (control concrete), C2 (concrete made with DMS as fine corrective sand) and C3 (concrete made with DMS as fine corrective sand and reinforced with plastic fibers $\mathrm{PF}$ ). The fresh and hardened properties obtained were compared with those of control mix.

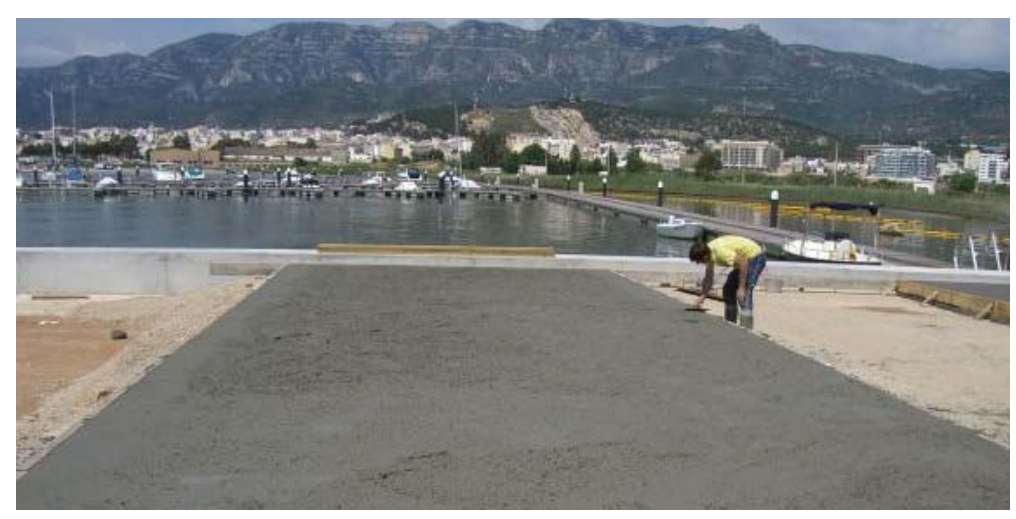

Figure 1. Pavement execution.

\section{Materials and experimental program}

\subsection{Materials}

Mix proportions on pastes and mortars considered initially: type II Portland cement, water, raw sand (NS1 0/2 mm), and different percentages of DMS. A policarboxilatebased plasticizer ( $\% \mathrm{P}$ by cement weight) was used in some pastes in order to evaluate fluidity and cohesion. Concrete production considered type II Portland cement for maritime environment exposure. Four fractions of limestone raw aggregates: fine aggregates FA1 $(0 / 2 \mathrm{~mm})$ and FA2 $(0 / 5 \mathrm{~mm})$; coarse aggregate CA1 $(5 / 12 \mathrm{~mm})$ and CA2 $(12 / 20 \mathrm{~mm})$ from the plant of Amposta-Masdenverge (UNILAND) were used for concrete production. Physical properties of the aggregates are summarized in table 1.

Table 1. Density and water absorption capacity of aggregates.

\begin{tabular}{lllllll}
\hline Physical properties & DMS & NS1 & FA1 & FA2 & CA1 & CA2 \\
\hline Density $^{*}\left(\mathrm{~kg} / \mathrm{dm}^{3}\right)$ & 2.63 & 2.65 & 2.7 & 2.69 & 2.7 & 2.7 \\
Absorption $(\%)$ & 1 & 0.4 & 0.4 & 0.7 & 0.8 & 0.4 \\
\hline
\end{tabular}

*Density on a saturated and surface -dried basis ASTM C-642. 
Polypropylene fiber (FORTA HIERRO ${ }^{\circledR}$, see table 2) was incorporated in C3 concrete with the objective of enhancing flexural resistance. Policarboxilate plasticizer $(\% \mathrm{P})$ was incorporated in the three concretes in order to achieve acceptable consistence for pumped casting.

Table 2. Plastic fiber characteristics (FORTA HIERROß).

\begin{tabular}{ll}
\hline Fiber characteristics & \\
\hline Materials & Virgin Copolymer/Polypropylene \\
Color & Gray \\
Form & Monofilament/Fibrillated \\
Fiber System Acid/Alkali Resistance & Excellent \\
Absorption & Nil \\
Tensile Strength & $620-758 \mathrm{MPa}$ \\
Compliance & A.S.T.M. C-1116 \\
Length & $54 \mathrm{~mm}$ \\
Specific Gravity & $0.91 \mathrm{~g} / \mathrm{cm}^{3}$ \\
\hline
\end{tabular}

\subsection{Experimental program}

With the aim of assessing DMS as construction material, fresh and hardened properties of pastes, mortars and concrete were evaluated. Preliminary tests were carried out on pastes and mortars in order to define DMS's role on concrete dosage. The objective was analysing possible DMS behaviour as additive and its influence in fluidity and cohesion of pastes. For this purpose, the use of a plasticizer was considered in some mixes. On the other hand, DMS incorporation on mortars aimed to evaluate its behaviour as fine corrective sand and its influence on compressive strength. The pastes and mortars were produced in a 5-liter Hobart-type blender with two speeds capacities according to ASTM C-305 specifications in laboratory at ambient temperature of $20 \pm 2^{\circ} \mathrm{C}$. Different percentages of DMS were used on pastes and mortars production considering cement and raw sand replacement. Normal consistence according to EN 196-3, Marsh cone EN 445 and mini slump according to AÏTCIN (2000) tests were carried out on pastes in order to evaluate consistence, fluidity and cohesion, respectively. On mortars, mechanical behaviour was studied according to EN 196-1.

With respect to concrete production, three different concretes were fabricated in a industrial plant: $\mathrm{C} 1$ control concrete made without DMS; C2 concrete made with DMS (on substitution of FA1) and C3 concrete made with DMS (on substitution of FA1) and reinforced with plastic fibers PF. Mechanical tests (compressive strength, elastic modulus, tensile strength with Barcelona-Test and flexural tensile strength) were carried out in order to establish hardened properties of concretes at 28 days of moist curing. Due to the marine environment exposure of structures, volume of permeable pores and capillary absorption tests were also carried out on extracted cores T1, T2 and T3 at 150 days after casting. 


\subsubsection{Mix composition}

Pastes:

Mix proportions considered initially: cement, water and different substitution or incorporation ratio of DMS by cement weight (see table 2). Mix composition of pastes considered the study of DMS behaviour as additive with the objective of assessing any possible pozzolanic or cementicial activity on its behaviour.

Table 2. Mix proportion of pastes

\begin{tabular}{lllllll}
\hline & \multicolumn{3}{l}{ Normal cconsistence } & \multicolumn{3}{l}{ Marsh cone and mini } \\
& \multicolumn{7}{c}{ slump } \\
\hline Materials & PN1 & PN2 & PN3 & P1 & P2 & P3 \\
\hline Cement (gr) & 500 & 375 & 250 & 1200 & 1200 & 1200 \\
DMS (gr) & - & 125 & 250 & - & 300 & 600 \\
Effective water(gr) & 120 & 100 & 90 & 600 & 600 & 600 \\
w/c & 0.24 & 0.27 & 0.36 & 0.5 & 0.5 & 0.5 \\
$\% P$ & - & - & - & $0-0.5-1$ & $0.5-1$ & $0.5-1-2$ \\
\hline
\end{tabular}

Pastes PN1, PN2 and PN3 submitted to normal consistence test were produced using DMS with substitution ratios of $0 \%, 25 \%$ and $50 \%$, respectively, by cement weight. Pastes P1, P2 and P3 were fabricated in order to evaluate fluidity and cohesion by Marsh cone and mini slump tests. Plasticizer content $(\% \mathrm{P})$ varying from 0 to $1 \%$ by cement weight as well as constant $\mathrm{w} / \mathrm{c}=0.5$ were used on the latter mixes. P2 and P3 incorporated $25 \%$ and $50 \%$ of DMS by cement weight.

Mortars:

Mortar mixes were produced with partial replacement of cement and raw sand by DMS. Dosage 1: 3: 0.5 (cement: sand: water) was adopted in all cases and plasticizer content $(\% \mathrm{P})$ was not used in these mortars production (see table 3$)$.

Table 3. Mix proportion of mortars

\begin{tabular}{lccccc}
\hline Material & M1 & M2 & M3 & M4 & M5 \\
\hline Cement (gr) & 500 & 375 & 250 & 500 & 500 \\
NS1 0-2 mm sand (gr) & 1500 & 1500 & 1500 & 1125 & 750 \\
DMS (gr) & - & 125 & 250 & 375 & 750 \\
Effective water (gr) & 250 & 250 & 250 & 250 & 250 \\
$\%$ DMS & $0 \%$ & $25 \%$ & $50 \%$ & $25 \%$ & $50 \%$ \\
\hline
\end{tabular}

Control mortar, M1, was made with $0 \%$ of DMS; M2 and M3 mortars were made with $25 \%$ and $50 \%$ of DMS, respectively, on substitution of cement. M4 and M5 mortar mixes were made with $25 \%$ and $50 \%$ of DMS on substitution of NS1, respectively. 


\section{Concrete:}

The mix proportions used in concretes production regarding to marine environment exposure were determined in the industrial plant (see table 4). Aggregate's humidity was corrected and the w/c ratio used considered the total amount of water present on the mixes.

Table 4. Concrete dosage.

\begin{tabular}{llll}
\hline Dosage & C1 & C2 & C3 \\
\hline Cement II /A-M 42.5 R (kg) & 335 & 345 & 345 \\
FA2: Fine aggregate $(\mathrm{kg})$ & 800 & 700 & 700 \\
FA1: Fine aggregate $(\mathrm{kg})$ & 100 & - & - \\
DMS: dredged sand $(\mathrm{kg})$ & - & 150 & 150 \\
CA1: Coarse aggregate $5 / 12(\mathrm{~kg})$ & 310 & 320 & 320 \\
CA2: Coarse aggregate $12 / 20(\mathrm{~kg})$ & 640 & 670 & 670 \\
Plastic fibers $\left(\mathrm{kg} / \mathrm{m}^{3}\right)$ & - & - & 4 \\
Water (litres) & 165 & 165 & 165 \\
Plasticizer $(\%$ by cement weight) & 0.74 & 0.73 & 0.94 \\
\hline
\end{tabular}

C1 corresponds to control concrete without DMS. Concretes C2 and C3 presented the same dosage with DMS incorporation of $150 \mathrm{~kg} / \mathrm{m}^{3}$ (replacing FA1 and partially FA2) except for the incorporation of plastic fibers on C3. A quantity of $4 \mathrm{~kg} / \mathrm{m}^{3}$ of polypropylene fibers with $54 \mathrm{~mm}$ length according to ASTM.C-1116 was incorporated in $\mathrm{C} 3$ concrete. The objective was enhancing the pavement flexural resistance and assessing DMS behaviour in the presence of plastic fibers. Coarse aggregates CA1 and CA2 were increased in $10 \mathrm{~kg} / \mathrm{m}^{3}$ and $30 \mathrm{~kg} / \mathrm{m}^{3}$, respectively, in order to maintain compressive strength with respect to control mix. In order to achieve acceptable consistence for pumped casting, a policarboxilate plasticizer was incorporated in the three concretes $(0.74 \%, 0.73 \%$ and $0.94 \%$, respectively, by cement weight).

\subsubsection{Tests performed}

Pastes:

Normal consistence (EN 196-3), Marsh cone (EN 445) and mini slump (AÏTCIN, 2000) tests were carried out on pastes with the objective of assessing fresh properties. Marsh cone test has been used by many researchers in the study of fluidity and determination of appropriate content of super plasticizers in the mixes. The test consists on preparing 1 litre of paste and measuring the time that $1 / 2$ litre of the paste takes to flow through the needle. Mini slump test procedure is described on AÏTCIN (2000) and consists on filling the mini slump with paste and recording the extension time in seconds from 10 $\mathrm{min}, 30 \mathrm{~min}, 40 \mathrm{~min}$ and $60 \mathrm{~min}$ of the mix fabrication. Final spread of $180 \pm 10 \mathrm{~mm}$ and 
corresponding spread time to reach $115 \mathrm{~mm}\left(\mathrm{~T}_{115}\right)$ around $3 \pm 1$ seconds indicates acceptable cohesion for mixes with optimum filler/cement ratio.

Mortars:

Hardened properties were determined on mortars by compressive and flexural strength tests (EN 196-1). At the age of 7 and 28 days prismatic samples with 40x40x160mm subjected to standard vibration and moist curing were tested.

Concrete:

Tests were carried out on concrete $\mathrm{C} 1, \mathrm{C} 2$ and $\mathrm{C} 3$ at 28 days: compressive strength according to UNE-EN 12390, elastic modulus UNE 83316, flexural tensile strength UNE-EN 14651, Barcelona test PrUNE 83-515, absorption and capillary suction UNE 83982. Barcelona test is an indirect tensile test based on the Double- Punching Test (DPT) formerly presented by CHEN (1970). Flexural tensile strength test analyses the tensile behaviour of fiber concrete in terms of residual flexural tensile strength values.

Cores T1, T2 and T3 were extracted from the pavement at 150 days in order to evaluate durability properties on time (volume of permeable pores and absorption ASTM C-642, capillary absorption coefficient UNE 83982, depth of water penetration under pressure UNE-EN 12390).

\subsubsection{Results on pastes}

Normal consistence:

In order to obtain the normal consistence on pastes PN1, PN2 and PN3 (with replacement of $0 \%, 25 \%$ and $50 \%$ of cement by DMS), water-cement ratio increased from 0.24 to 0.27 in PN2 and to 0.36 in PN3. Results indicate slight water demand increase in PN2 comparing to control mix PN1. PN3 presented the highest water demand comparing to the mixes tested.

Marsh cone on pastes:

Pastes P2 and P3 with constant $\mathrm{w} / \mathrm{c}=0.5$ considered the incorporation of $25 \%$ and $50 \%$, respectively, of DMS by cement weight with the aim of verifying the effect of DMS on the fluidity of the mixes in comparison to control mix P1. It can be observed (table 5) that once DMS content raises the mix fluidity diminishes. However, for $25 \%$ of DMS incorporation P2 flow time presented negligible variation comparing to control mix P1. Different behaviour was observed on mixes P3 with 50\% of DMS incorporation where flow times presented considerable increase.

Test results indicates, for constants $\mathrm{w} / \mathrm{c}$ and plasticizer content $\% \mathrm{P}$, higher flow time values when $50 \%$ of DMS is incorporated to the mixes comparing to those with $0 \%$ and $25 \%$. This highlights the influence on DMS on the fluidity loss of the mixes once its incorporation ratio is increased. 
Table 5. Flow time on pastes.

\begin{tabular}{llll}
\hline \multicolumn{4}{l}{ Flow time on pastes } \\
\hline$\% \boldsymbol{P}$ & $\boldsymbol{T}$ (sec) & \\
\hline 0,0 & 20 & 28 & 45 \\
0,5 & 12 & 19 & 39 \\
1,0 & 10 & 14 & 21 \\
2,0 & - & - & 15 \\
$\% D M S$ & $0 \%(P 1)$ & $25 \%(P 2)$ & $50 \%(P 3)$ \\
\hline
\end{tabular}

Mini slump on pastes

In order to evaluate cohesion on pastes, mini slump tests were carried out on mixes $(\mathrm{w} / \mathrm{c}=0.5)$ with $0 \%(\mathrm{P} 1), 25 \%(\mathrm{P} 2)$ and $50 \%(\mathrm{P} 3)$ of DMS incorporation by cement weight. $\mathrm{P} 1$ revealed decreasing spread diameter once plasticizer content $(\% \mathrm{P})$ risest. On the other hand, the presence of DMS on P2 revealed increasing spread diameter in comparison to control mix when plasticizer content rises (table 6). Slight diameter variation was observed on P3 thus indicating additive effectiveness loss due to the high amount of DMS considered. Studies (GOMES, 2002) revealed that final spread diameter of mini slump usually presents higher values once additives contents are raised and small fillers contents are incorporated to the mixes. Although DMS used in this study presents mineral characteristics rather similar to sands than to fillers, the incorporation of $25 \%$ of DMS improved the mixes cohesion with no segregation observed. However, none of the mixes achieved target values according to AÏTCIN (2000).

Table 6. Mini slump test results on pastes.

\begin{tabular}{|c|c|c|c|c|c|c|c|c|c|c|}
\hline \multicolumn{11}{|c|}{ Mini Slump - Spread diameter on pastes } \\
\hline \multirow{2}{*}{$\frac{d(\mathrm{~cm})}{d_{10}}$} & \multicolumn{3}{|c|}{$P 1: 0 \% D M S$} & \multicolumn{3}{|c|}{$P 2: 25 \% D M S$} & \multicolumn{4}{|c|}{$P 3: 50 \% D M S$} \\
\hline & 10.1 & 8.5 & 7.65 & 9 & 10 & 12.5 & 8.4 & 8.6 & 10 & 11 \\
\hline$d_{20}$ & 12.5 & 7.8 & 7.35 & 8.6 & 9.8 & 13.5 & 8.2 & 8.8 & 9.4 & 9.5 \\
\hline$d_{30}$ & 12.95 & 8 & 7.5 & 8.8 & 9.2 & 13.5 & 8.1 & 8.5 & 9.1 & 8.8 \\
\hline$d_{40}$ & 13.15 & 8.6 & 6.3 & 8.5 & 9.5 & 13.5 & 8 & 8.4 & 8.7 & 8.8 \\
\hline$\% P$ & 0 & 0.5 & 1 & 0 & 0.5 & 1 & 0 & 0.5 & 1 & 2 \\
\hline
\end{tabular}

\subsubsection{Results on mortars}

\section{Compressive strength on mortars}

Compressive strength revealed that M4 presented better results with 3\% higher compressive strength than M1 (table 7) at 28 days. Due to fine grading distribution of DMS, its adequate use as corrective sand with NS1 substitution ratio around 25\% was checked. 
Table 7. Compressive strength of the mortars.

\begin{tabular}{llllll}
\hline \multicolumn{5}{c}{ Compressive strength (MPa) } \\
\hline Age (days) & $M 1$ & $M 2$ & $M 3$ & $M 4$ & $M 5$ \\
\hline 7 days & 41.2 & 19.29 & 8.71 & 33.63 & 22.07 \\
28 days & 50.05 & 23.76 & 12.53 & 51.57 & 36.81 \\
\hline
\end{tabular}

\subsubsection{Test results in concrete}

$\mathrm{C} 1, \mathrm{C} 2$ and $\mathrm{C} 3$ concretes satisfied the minimum of $30 \mathrm{MPa}$ compressive strength at 28 days defined for this project (see Table 8). Each presented value is the average of three measurements. With reference to modulus of elasticity, $\mathrm{C} 1$ and $\mathrm{C} 2$ obtained similar values. C3 obtained the lowest value probably due to extra content of plasticizer added in concrete production and the presence of plastic fibers.

Table 8. Mechanical properties of concretes.

\begin{tabular}{ccccc}
\hline \multirow{2}{*}{ Concrete } & $\begin{array}{c}\text { Compressive } \\
\text { strength } \\
(\mathbf{M P a})\end{array}$ & $\begin{array}{c}\text { Elastic } \\
\text { modulus } \\
(\mathbf{M P a})\end{array}$ & $\begin{array}{c}\text { Flexural- } \\
\text { tensile } \\
\text { strength }(\mathbf{M P a})\end{array}$ & $\begin{array}{c}\text { Tensile } \\
\text { strength (MPa) }\end{array}$ \\
\hline$C 1$ & $39(5 \%)$ & $28,500(2,2 \%)$ & $4.02(10 \%)$ & $2.56(7 \%)$ \\
$C 2$ & $36(4 \%)$ & $26,500(1,2 \%)$ & $3.67(10 \%)$ & $2.53(3 \%)$ \\
$C 3$ & $33(5 \%)$ & $24,500(0,2 \%)$ & $3.47(10 \%)$ & $2.41(12 \%)$ \\
\hline
\end{tabular}

The tensile strength determined by the Barcelona-Test (PrUNE 83-515) presented results around 2.5 $\mathrm{MPa}$. Negligible variation was observed on the results revealing slight influence of DMS on the tensile strength of the concretes studied. All concrete mixes satisfied the minimum of $3 \mathrm{MPa}$ flexural tensile strength at 28 days. $\mathrm{C} 1$ presented $4 \mathrm{MPa}$ followed by $\mathrm{C} 2$ and $\mathrm{C} 3$ concretes with respective values of $3.7 \mathrm{MPa}$ and 3.5 MPa. Experimental studies reveal (BENCARDINO et al., 2008) similar results of residual flexural tensile strength for fiber reinforced concretes fabricated with equivalent mix proportion and using ordinary aggregates.

Durability tests carried out in this study are summarized in table 9 for concretes C1, C2 and $\mathrm{C} 3$ at the age of 28 days and for cores T1, T2 and T3 at the age of 150 days.

Concrete $\mathrm{C} 1$ obtained the lowest volume of permeable pores and lowest capillary absorption coefficient followed by $\mathrm{C} 2$ (concrete using DMS on substitution of FA1) and C3 (concrete using DMS and plastic fiber PF). This effect can be attributed to higher effective w/c ratio of $\mathrm{C} 2$ and $\mathrm{C} 3$ concretes once water absorption capacity of DMS was lower than FA1.Tests results for permeable pore volume on cores T1, T2 and T3 presented slight deviation among different cores measurement of same type of concretes. The water penetration depth (under pressure) value of T1, T2 and T3 pavements cores were lower than the maximum value $(5 \mathrm{~cm})$ required by Spanish standard of structural concrete (EHE, 2008) for mass concrete exposed to air marine 
environment. Corresponding absorption coefficients of T1, T2 and T3 are summarized in table 9.

Table 9. Durability tests results on concretes.

\begin{tabular}{llllll}
\hline Concrete & $\begin{array}{l}\text { Volume of permeable } \\
\text { pores (\%) }\end{array}$ & $\begin{array}{l}\text { Capillary absorption } \\
\text { coefficient }\left(\mathbf{c m} / \boldsymbol{h}^{\mathbf{1}}\right)\end{array}$ & Absorption (\%) & Water penetration (cm) \\
\hline$C 1$ & 8.97 & 0.0441 & - & - & \\
$C 2$ & 10.05 & 0.0558 & - & - & \\
$C 3$ & 11.57 & 0.0632 & - & - & \\
\hline$T 1$ & $13.4(4 \%)$ & 0.0274 & $5.9(5 \%)$ & 2.03 & 1.14 \\
$T 2$ & $12.7(1 \%)$ & 0.023 & $5.5(3 \%)$ & 0.90 & 1.60 \\
$T 3$ & $12.9(4 \%)$ & 0.0236 & $5.6(4 \%)$ & - & 0.92 \\
\hline
\end{tabular}

\section{Conclusions}

- Paste made with $25 \%$ of DMS addition showed adequate fluidity. However, target values for cohesion according to AÏTCIN (2000) were not achieved. The addition of $50 \%$ produced huge loss of fluidity and no cohesion improvement;

- Mortar made with 25\% of DMS on substitution of raw sand (NS1) presented similar compressive strength to control mortar at 7 and 28 days;

- Tests results on pastes and mortars revealed DMS feasibility as corrective sand rather than addition;

- Mechanical properties (compressive strength, elastic modulus, tensile strength with Barcelona-Test and flexural tensile strength) of concretes made with DMS on substitution of fine sand $(0-2 \mathrm{~mm})$ were similar to those of control concrete;

- Concrete C3 obtained lower mechanical properties than control concrete at 28 days of curing. This effect can be attributed to its higher plasticizer content and the presence of polypropylene fibers;

- Control concrete obtained the lowest volume of permeable pores and absorptivity while $\mathrm{C} 3$ obtained the highest values probably due to: higher effective water (higher plasticizer content) and the presence of $\mathrm{PF}$ which increases its porosity matrix;

- Concrete harbour pavements produced with DMS obtained adequate properties according to water penetration depth under pressure;

- The experimental results obtained in this work show that fine sandy dredged sediment studied can be successfully used as a fine aggregate for concrete production. It is an acceptable material for construction of a harbor road pavement with concrete of $30 \mathrm{MPa}$;

- Further research is being developed with three different DMS from Barcelona's Port in order to validate its positive behaviour as fine aggregate for harbor concrete pavement. The objective is to assess the effect of higher content of DMS on the mixes. 
Thème 7 - Gestion et valorisation des sédiments marins

\section{References}

AÏTCIN P.C. (2000). High Performance Concrete.

ASTM.C-305. Standard Practice for Mechanical Mixing of Hydraulic Cement Pastes and Mortars of Plastic Consistency.

ASTM C-642. Standard Test Method for Density, Absorption, and Voids in Hardened Concrete.

ASTM.C-1116. Standard Specification for Fiber-Reinforced Concrete.

BENCARDINO F., RIZZUTI L., SPADEA G., SWAMY R.N. (2008). Stress-strain behaviour of steel fibers-reinforced concrete in compression. Journal of materials in civil engineering. ASCE, pp 255-263. doi:10.1061/(ASCE)0899-1561(2008)20:3(255)

CHEN W.F. (1970). Double punch test for tensile strength of concrete. ACI Mater J 67(2), pp 993-995.

EN 196-1. Methods of testing cement - Part 1: Determination of strength.

EN 196-3. Methods of testing cement - Determination of setting times and soundness.

EN 445. Grout for prestressing tendons - Test methods.

GOMES P.C.C. (2002). Optimization and characterization of high-strength selfcompacting concrete, Doctoral thesis, UPC, Barcelone.

LIMEIRA J., AGULLO L., ETXEBERRIA M. (in press). Dredged marine sand in concrete: An experimental section of a harbor pavement. Constr Build Mater, doi:10.1016/j.conbuildmat.2009.12.011

PrUNE 83-515. Determination of cracking resistance, toughness and residual tension. Barcelona Test, Madrid, Spain.

UNE 83316. Determination of the modulus of elasticity in compression.

UNE 83982. Determination of the capillary suction in hardened concrete.

UNE-EN 12390. Testing hardened concrete - Compressive strength of test specimens.

UNE-EN-14651. Test method for metallic fiber concrete - Measuring the flexural tensile strength (limit of proportionality (LOP), residual). 